\title{
Viabilidade agronômica do consórcio de alface e rúcula, em duas épocas de cultivo
}

\author{
Caciana Cavalcanti Costa ${ }^{1}$; Arthur Bernardes Cecílio Filho²; Bráulio Luciano Alves Rezende³ ${ }^{3}$ José \\ Carlos Barbosa'; ${ }^{2}$ Leilson Costa Grangeiro ${ }^{4}$ \\ ${ }^{1}$ UCC - CCTA, Rua Cel. João Leite, 517, Centro, 58840-000 Pombal-PB; ${ }^{2}$ UNESP-FCAV, Via de acesso Prof. Paulo D. Castellane, s/n, \\ 14884-900 Jaboticabal-SP; Bolsista CNPq; ${ }^{3}$ Doutorando; ${ }^{4}$ UFERSA depto. Fitotecnia, C. Postal 137, 59625-900 Mossoró-RN; E-mail: \\ rutra@fcav.unesp.br; leilson@ufersa.edu.br
}

\section{RESUMO}

Avaliou-se a produtividade de grupos de alface e da rúcula, em consórcio, em relação aos seus cultivos solteiros, na UNESP Jaboticabal, em condições de campo, em duas épocas de cultivo, maio a agosto e setembro a novembro de 2001, sob delineamento de blocos casualizados, com quatro repetições. Os tratamentos constaram de combinações dos fatores grupos de alface (crespa, cv. Vera; lisa, cv. Elisa e americana, cv. Tainá), sistemas de cultivo (consórcio e cultivo solteiro) e épocas de semeadura da rúcula para o estabelecimento do consórcio [0; 7 e 14 dias após o transplante (DAT) da alface]. As maiores matérias fresca e seca de alface foram obtidas na primavera, com destaque para a alface americana. As alfaces não foram afetadas pelo sistema de cultivo. A maior matéria fresca de rúcula, no outono-inverno, foi obtida em consórcio, a 0 DAT, com as alfaces crespa e lisa e, aos 7 DAT com americana, enquanto na primavera, quando foi consorciada aos 7 DAT com alface crespa e a 0 DAT com alfaces do grupo lisa e americana. A rúcula teve sua matéria seca reduzida nos consórcios estabelecidos tardiamente, aos 14 DAT. Os cultivos consorciados apresentaram-se superiores aos cultivos solteiros entre 5 e 93\%, segundo o índice de uso eficiente da terra. Os maiores índices de uso eficiente da terra foram obtidos com os consórcios de rúcula e alface crespa a 0 DAT $(1,93)$, no outono-inverno e pelas mesmas hortaliças aos 7 DAT $(1,84)$, na primavera.

Palavras-chave: Lactuca sativa, Eruca sativa, sistema de cultivo, uso eficiente da terra, produtividade, consorciação.

\begin{abstract}
Agronomic viability of lettuce-roquette intercropping in two growing periods

The productivity of different lettuce groups and roquette was evaluated when sown in two different periods and cultivated either singly or intercropped. Theses experiments were carried out in Jaboticabal, São Paulo State, Brazil. The first growing period was from May to August (Autumn-Winter) and the second from September to November (Spring) of 2001. The experimental design was a randomized complete block with four replications. The treatments consisted of the combination of the following factors levels: lettuce groups (crisp, cv. Vera; looseleaf, cv. Elisa; and crisphead lettuce, cv. Tainá), cropping systems (intercropping and sole crop) and roquette sowing times [0; 7, and 14 days after lettuce transplantating (DAT)]. The highest fresh and dry matter production were observed for crisphead lettuce in the Spring. The cropping systems did not affect the lettuce groups productivity. The highest roquette fresh matter production was observed in the Autumn-Winter period at 0 DAT, with the crisp and looseleaf lettuce, and at 7 DAT with crisphead lettuce. For the Spring period the highest roquette fresh matter production was observed at 7 DAT with crisp lettuce and at 0 DAT with looseleaf and the crisphead lettuce. Roquette dry matter was reduced in the intercropping at 14 DAT. The intercropping system yielded 5 to $93 \%$ more than the single system according to the land equivalent ratio. The highest land equivalent ratio was observed in the roquette-crisp lettuce intercropping at 0 DAT the crisp variety (1.93) in the Autumn-Winter, while the highest ratio was observed at 7 DAT (1.84) in the Spring.
\end{abstract}

Keywords: Lactuca sativa, Eruca sativa, cropping system, land equivalent ratio, productivity, intercropping.

\section{(Recebido para publicação em 04 de janeiro de 2006; aceito em 18 de abril de 2007)}

\begin{abstract}
$\mathrm{A}$ olericultura proporciona considerável impacto ambiental pelo intenso emprego de insumos e de recursos naturais. Atualmente, a consorciação de culturas, ainda que de forma incipiente, vem sendo empregada como tecnologia para reduzir danos ao ambiente, uma vez que pelo maior número de plantas por área, tem-se maior e mais rápida cobertura do solo e, consequentemente, menor erosão (eólica e pluvial) e maior aproveitamento de água, fertilizantes e defensivos (Cecílio Filho \& May, 2002).

O grande benefício do sistema consorciado é a possibilidade de maior
\end{abstract}

rendimento por área, em função do aumento ou compensação da produtividade das culturas componentes do consórcio (Gliessman, 2004). Outra vantagem consiste na diversificação dos produtos colhidos pelo produtor (Rezende et al., 2005c); estabilidade de produção em diferentes estações (Zaffaroni et al., 1987) e maior retorno econômico (Adelana, 1984; Rezende et al., 2005b, 2005c). Em geral, estas vantagens são proporcionadas, por maior eficiência na utilização dos recursos ambientais (Gliessman, 2004), pelo uso mais efi- ciente de água (Soetedjo et al., 2005) e redução na infestação de plantas daninhas (Adelana, 1984), ambas pelo efeito de cobertura do solo.

Várias são as possibilidades de consórcios de hortaliças, e dentre elas, as pesquisas também têm demonstrado que a alface (Caetano et al., 1999; Cecílio Filho \& May, 2002; Tolentino Junior et al., 2002; Gliessman, 2004; Rezende et al., 2005a, 2005b) tem sido promissora no cultivo consorciado. A rúcula vem sendo utilizada como cultura intercalar a outras hortaliças (França et al., 2004; 
Rezende et al., 2005b), principalmente por apresentar preço elevado entre as folhosas.

A eficiência do consórcio depende diretamente do sistema e das culturas envolvidas, havendo a necessidade da complementação entre essas (Bezerra Neto et al., 2003). No planejamento de cultivos consorciados, a época de estabelecimento é um fator importante, pois o período de convivência entre as espécies pode afetar a produtividade das culturas (Cecílio Filho \& May, 2002). Também é imprescindível fazer a escolha certa das combinações de espécies ou cultivares, pois uma das dificuldades para o estabelecimento dos consórcios é a falta de informações sobre características das plantas mais interessantes e adequadas para o sistema. Isto se deve ao fato das cultivares utilizadas no consórcio serem desenvolvidas para monocultivo, com uso de tecnologias e manejos diferentes das utilizadas nos consórcios (Carvalho, 1993), e com isso, muitas vezes, a sua associação pode não resultar nas melhores respostas.

O presente trabalho teve como objetivo avaliar a produtividade e a eficiência do uso da terra de consórcios de alface dos grupos crespa, lisa e americana com rúcula, em duas épocas de cultivo.

\section{MATERIAL E MÉTODOS}

Os experimentos foram conduzidos em campo, em duas épocas de cultivo, de 21/05 a 05/08 e de 01/09 a 19/11/01, no Setor de Olericultura e Plantas Aromático-medicinais, do Departamento de Produção Vegetal, da Faculdade de Ciências Agrárias e Veterinárias, da UNESP em Jaboticabal, SP.

O solo da área foi classificado como LATOSSOLO VERMELHO Eutroférrico típico de textura muito argilosa, A moderado caulinítico-oxídico, cujas características químicas, em préinstalação do primeiro experimento, foram $\mathrm{pH}\left(\mathrm{CaCl}_{2}\right)$ de 5,$5 ; 31 \mathrm{~g} \mathrm{dm}^{-3}$ de M.O.; $139 \mathrm{mg} \mathrm{dm}^{-3}$ de $\mathrm{P}$ (resina); $\mathrm{K}=2,6$ $\mathrm{mmol}_{\mathrm{c}} \mathrm{dm}^{-3} ; \mathrm{Ca}=27,8 \mathrm{mmol}_{\mathrm{c}} \mathrm{dm}^{-3} ; \mathrm{Mg}=$ $15,8 \mathrm{mmol}_{\mathrm{c}} \mathrm{dm}^{-3}$ e $\mathrm{V}=72 \%$.

Durante a condução do experimento no outono-inverno, os valores médios registrados para as características climatológicas foram de 69,5\% de umidade relativa, $0,3 \mathrm{~mm}$ de precipitação, $7,9 \mathrm{~h}$ de insolação e temperaturas média de $20,3^{\circ} \mathrm{C}$, média das temperaturas máximas $27,3^{\circ} \mathrm{C}$ (com variações entre 14 e $31,6^{\circ} \mathrm{C}$ ) e mínimas $13,4^{\circ} \mathrm{C}$ (variando entre $5,3 \%$ e $18,4^{\circ} \mathrm{C}$ ). Na primavera foram observadas médias de $64,3 \%$ de umidade relativa, $3,2 \mathrm{~mm}$ de precipitação, 7,4 h de insolação e $23,9^{\circ} \mathrm{C}$ de temperatura, com máxima de $30,1^{\circ} \mathrm{C}(21,6$ $\left.35,6^{\circ} \mathrm{C}\right)$ e mínima de $17,6^{\circ} \mathrm{C}(10,3-$ $21,8^{\circ} \mathrm{C}$ ), respectivamente.

As cultivares de alface dos grupos crespa, lisa e americana foram, respectivamente Vera, Elisa e Tainá, e a de rúcula foi a Cultivada.

As unidades experimentais com área total de $1,44 \mathrm{~m}^{2}(1,20 \times 1,20 \mathrm{~m})$, foram constituídas por 16 plantas de alface nos tratamentos com crespa e lisa e por 12 plantas nos tratamentos com a americana. Nos consórcios, a rúcula foi semeada nas entrelinhas da alface; nestes sistemas de cultivo, a alface foi considerada a principal cultura e a rúcula, a secundária. Para cada experimento (época de cultivo), utilizou-se o delineamento de blocos casualizados, com quatro repetições, em esquema fatorial $3 \times 4$ para a cultura da alface, com os fatores grupos de alface (crespa, lisa e americana) e sistemas de cultivo (cultivo solteiro e consórcios aos 0; 7 e 14 dias após o transplante). Para a rúcula, adotou-se fatorial de $3 \times 2 \times 3$, respectivamente representados pelos fatores grupos de alfaces (crespa, lisa e americana), sistemas de cultivo (cultivo solteiro e consórcio) e épocas do estabelecimento dos consórcios (0, 7 e 14 DAT da alface).

Em cada experimento foram avaliados 21 tratamentos, sendo que os tratamentos 1; 2 e 3 corresponderam aos consórcios da alface crespa com a rúcula semeada aos $0 ; 7$ e 14 DAT. Os tratamentos 8; 9 e 10; e 15 ; 16 e 17 , respectivamente, corresponderam aos consórcios de alface dos grupos lisa e americana, com a rúcula semeada aos $0 ; 7$ e 14 DAT. Os tratamentos 4; 11 e 18 corresponderam aos cultivos solteiros das alfaces dos grupos crespa, lisa e americana, enquanto $5 ; 6$ e $7 ; 12 ; 13$ e 14, e 19; 20 e 21 , respectivamente, representaram os monocultivos da rúcula nas mes- mas épocas de estabelecimento dos consórcios (0; 7 e 14 DAT) com cada grupo de alface.

Com base na análise química do solo, optou-se em não fazer a calagem e a adubação de plantio. A adubação de cobertura foi realizada, para cada hortaliça em cultivo solteiro e em consórcio, seguindo-se a recomendação de Trani et al. (1997). Para a cultura da alface foi aplicado $0,80 \mathrm{~g}_{\text {planta }}{ }^{-1}$ de uréia, aos 10; 20 e 30 DAT e para a cultura da rúcula utilizaram-se $3 \mathrm{~g} \mathrm{~m}^{-1}$ de uréia, aos 7; 14 e 21 dias após a germinação da rúcula.

Nos cultivos da primeira e segunda época, as alfaces foram semeadas, respectivamente em 21/05 e em 01/09, utilizando-se bandejas de 128 células. As mudas foram transplantadas quando apresentavam quatro folhas definitivas, aos 24 dias (14/06) e 25 dias (26/09) após a semeadura (DAS) na primeira (outono-inverno) e na segunda (primavera) época de cultivo, respectivamente. A rúcula foi semeada diretamente no canteiro e o desbaste realizado aos 10 DAS, para a adequação do espaçamento entre plantas na linha.

Nos cultivos solteiro e consorciado, as alfaces crespa e lisa foram transplantadas no espaçamento de $0,30 \times 0,30 \mathrm{~m}$ e a americana em 0,40 x 0,30 m. A rúcula em cultivo solteiro foi semeada no espaçamento $0,25 \times 0,05 \mathrm{~m}$ e no consórcio foi semeada nas entrelinhas da alface, mantendo-se o espaçamento entre plantas em 0,05 m.

Para o controle de plantas daninhas nas culturas, aplicou-se herbicida em pré-plantio das culturas e, durante a condução das culturas, foram realizadas capinas manuais. Também foram realizados tratos fitossanitários com fungicida e inseticidas nas culturas, para prevenção de pragas e doenças. A irrigação foi realizada pelo sistema de aspersão, com lâmina de 5 e 7 mm diários respectivamente, no cultivo do outonoinverno e primavera.

No outono-inverno, a colheita da alface crespa, lisa, americana e da rúcula foi, respectivamente, aos 40, 40, 52 DAT e 35 DAS. Na primavera, a colheita foi aos 40, 40, 48 DAT e 35 DAS. Todas as colheitas foram realizadas entre 7 e 9 horas da manhã. 
Tabela 1. Matéria fresca e seca de alface, em função dos grupos de alface e das épocas de cultivo (Fresh and dry matter as function of the groups and cultivation dates of lettuce). UNESP, Jaboticabal, 2005

\begin{tabular}{lcc}
\hline Grupos de alfaces & Matéria fresca (g planta $\left.^{-1}\right)$ & Matéria seca(g planta $\left.{ }^{-1}\right)$ \\
\hline Crespa & $301,04 \mathrm{~b}^{1}$ & $16,61 \mathrm{~b}$ \\
Lisa & $302,72 \mathrm{~b}$ & $17,84 \mathrm{~b}$ \\
Americana & $623,00 \mathrm{a}$ & $33,38 \mathrm{a}$ \\
DMS & 72,84 & 3,65 \\
\hline Épocas de cultivo & \\
\hline Outono-inverno & $316,71 \mathrm{~b}$ & $14,94 \mathrm{~b}$ \\
Primavera & $501,13 \mathrm{a}$ & $30,27 \mathrm{a}$ \\
DMS & 47,73 & 2,39 \\
\hline C.V. $(\%)$ & 19,40 & 20,67
\end{tabular}

${ }^{1}$ Para cada característica, médias na mesma coluna seguidas por letras minúsculas distintas, diferem significativamente a $5 \%$ de probabilidade pelo Teste de Tukey ( ${ }^{1}$ For each characteristic, means in the same column followed by little letters, differ significantly in the Tukey test (5\% probability)).

Avaliaram-se a matéria fresca e seca da alface $\left(\mathrm{g} \mathrm{planta}^{-1}\right)$, a matéria fresca e seca da parte aérea de rúcula $\left(\mathrm{g} \mathrm{m}^{-1}\right)$ e o índice de uso eficiente da terra (UET) proposto por Willey (1979). As produtividades das culturas foram estimadas em $\mathrm{kg}$ por área efetiva do canteiro $\left(1,60 \mathrm{~m}^{2}\right)$, antes de serem utilizadas no cálculo do índice de uso eficiente da terra, uma vez que existem diferenças entre as populações de plantas nos sistemas de cultivo.

As características relativas às alfaces dos grupos crespa e lisa foram avaliadas nas quatro plantas centrais da parcela. Para alface americana, utilizaramse as duas plantas centrais. Para a rúcula, avaliaram-se as plantas no metro central das linhas de cultivo dos consórcios, enquanto no cultivo solteiro o procedimento foi adotado apenas nas duas linhas internas do canteiro.

Foi realizada análise de variância conjunta dos dados dos dois experimentos (épocas de cultivo: outono-inverno e primavera).

\section{RESULTADOS E DISCUSSÃO}

A análise conjunta dos experimentos mostrou não haver interação significativa entre os tratamentos e as épocas de cultivo, na matéria fresca e seca das plantas de alface. Entretanto, foi constatado efeito isolado dos grupos de alface e das épocas de cultivo (Tabela 1). A matéria fresca e seca da alface em cultivo solteiro não diferiu das obtidas em consorciação com rúcula, independente do período de convivência entre as culturas. A matéria fresca média da alface foi de $416,75 \mathrm{~g}$ por planta.
Os resultados do presente trabalho concordam com os obtidos por Rezende (2004) que não verificou efeito significativo dos sistemas de cultivo (consórcio e cultivo solteiro) sobre a matéria fresca e seca das plantas da alface cresrepolho, com pimentão e rúcula, e com pimentão e rabanete. Também Tolentino Junior et al. (2002) não observaram diferenças entre o consórcio da alface cv. Grand Rapids com mandioquinha-salsa. Os autores atribuíram a ausência de competição, provavelmente, às diferenças no crescimento das plantas de cada espécie até a colheita.

Quanto ao efeito dos grupos de alface, verificou-se que a alface americana apresentou maior matéria fresca e seca. As alfaces dos grupos crespa e lisa não diferiram entre si (Tabela 1). A influência do fator grupos de alface se deve às diferenças morfológicas existentes entre os três grupos avaliados. Em uma avaliação de cultivares de alface dos grupos crespa, lisa e americana, em cultivos no solo e em hidroponia, nas quatro estações do ano, em Jaboticabal, verificou-se maior número de folhas em plantas do grupo lisa ou crespa, mas maior matéria fresca para americana e crespa na primavera, e na alface americana nos cultivos de verão e outono (Branco, 2001). A ausência de correlação entre o número de folhas e a massa se deve justamente às características morfológicas das cultivares, uma vez que as folhas da alface americana são mais espessas. Também em Jaboticabal, Figueiredo et al. (2004), no inverno-pripa 'Vera', consorciada com pimentão e mavera (11/08 a 01/11/01) e no outono (02/04 a 27/06/02) verificaram maiores matérias secas de plantas do grupo americana (cvs. Laidy, Tainá, Lucy Brown e Raider) comparadas àquelas do grupo lisa (cvs. Babá de Verão, Karla, Nacional e Elisa) e ao grupo de alface crespa (cvs. Simpson, Hortência, Verônica e Grand Rapids), sendo que o grupo lisa apresentou os menores valores.

A matéria fresca $\left(501,13 \mathrm{~g}_{\text {planta }}{ }^{-1}\right) \mathrm{e}$ seca $\left(30,27 \mathrm{~g}\right.$ planta $\left.^{-1}\right)$ da alface na primavera foram superiores em aproximadamente 58 e $102 \%$, respectivamente, em relação ao outono-inverno (Tabela 1). Esta diferença, possivelmente ocorreu por uma melhor disponibilidade térmica (graus-dia) para as plantas no período que estiveram no campo. Considerando-se a temperatura base de $10^{\circ} \mathrm{C}$, segundo proposta de Brunini et al. (1976), no cultivo da primavera obteve-se 563,60 graus-dia para a alface crespa e lisa e de 690,80 graus-dia para a alface americana, enquanto no outono-inverno estes índices foram de apenas 379,45 graus-dia para as alfaces crespa e lisa e de 503,75 para a alface americana.

Houve interação significativa entre os tratamentos e as épocas de cultivo para a matéria fresca da parte aérea da rúcula. No outono-inverno ocorreu interação entre os fatores grupos de alfaces, sistemas de cultivo e épocas de semeadura da rúcula (Tabela 2). Ao observar o comportamento dos sistemas de cultivo dentro das épocas de semeadura da rúcula para os diferentes grupos de alface, no outono-inverno, verificou-se que não houve diferença entre o consórcio e o cultivo solteiro para a matéria fresca da rúcula ao $0 \mathrm{DAT}$, quando consorciada com alface crespa e lisa, e aos 7 DAT para o consórcio com a americana. Nestes casos, as plantas de alface e rúcula promoveram melhor uso dos recursos ambientais.

A semeadura da rúcula efetuada aos 7 DAT nas entrelinhas da alface crespa, aos 7 e 14 DAT na lisa e aos 14 DAT na alface americana, promoveu redução na matéria fresca da rúcula. O atraso na semeadura da rúcula determinou diminuição na matéria fresca, resultado da maior competição da alface sobre a rúcula, com exceção feita à rúcula consorciada com alface crespa. Atrasos na semeadura da rúcula em relação à beterraba também causaram decréscimos na produtividade de rúcula, em inten- 
Tabela 2. Matéria fresca de rúcula, em função da interação de grupos de alface, sistema de cultivo e época de semeadura da rúcula no outonoinverno, e em função das interações de grupos de alface e sistema de cultivo; grupos de alface e época da semeadura da rúcula e sistema de cultivo e época de semeadura da rúcula na primavera (Fresh weight of roquette as function of the interaction of lettuce groups, cultivation system and sowing period from roquette on autumn-winter, as a function of the interactions of lettuce groups and cultivation systems; groups of lettuce and sowing period of roquette and cultivation system and sowing period of roquette in spring). UNESP, Jaboticabal, 2005.

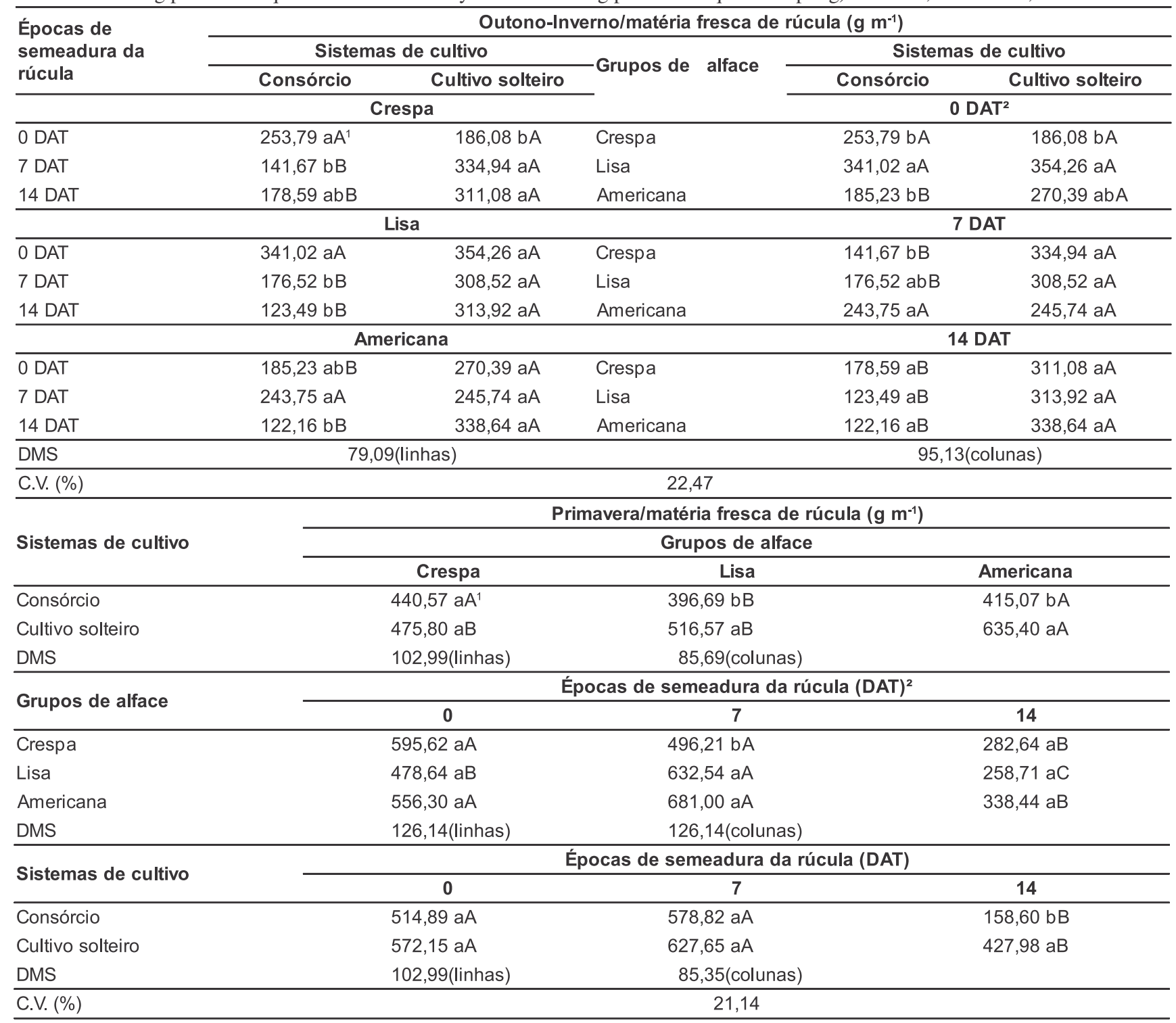

${ }^{1}$ Para cada interação, médias na mesma coluna seguidas por letras minúsculas diferentes e na mesma linha seguidas por letras maiúsculas distintas, diferem significativamente a $5 \%$ de probabilidade pelo Teste de Tukey, ${ }^{2} \mathrm{DAT}=$ dias após o transplante da alface $\left({ }^{1} \mathrm{For}\right.$ each interaction, means in the column followed by little different letters, and in the same line followed by head letters, differ significantly through Tukey test, $5 \%$ probability; ${ }^{2} \mathrm{DAT}=$ days after transplanting date of lettuce).

sidades crescentes à medida que mais tardia foi a semeadura da rúcula em relação aos transplante da beterraba (Nardin et al., 2002; Cecílio Filho et al., 2003).

As matérias frescas de rúcula em consórcio com a alface crespa e lisa apresentaram, respectivamente, aos 7 DAT, reduções de 44 e $48 \%$, em comparação à semeadura na mesma época do transplante da alface. Aos 14 DAT da alface lisa, o decréscimo na matéria fresca da rúcula atingiu 64\%. Prova- velmente, a partir dos 7 DAT, apesar das plantas de alface ainda apresentarem-se pequenas, já proporcionavam cobertura do solo suficiente para promover sombreamento às plantas de rúcula, visto que no consórcio com alface americana, que possui um maior espaçamento entre as linhas $(40 \mathrm{~cm})$, resultando em maior distância $(20 \mathrm{~cm})$ entre as culturas em consórcio, observou-se que o período de interferência da alface sobre a rúcula foi atrasado para 14 DAT, com reduções de aproximadamente 50\%. Esses resultados assemelham-se ao consórcio de rúcula e chicória, a qual possui arquitetura e espaçamento semelhante ao da alface americana. França et al. (2004) também observaram interferência da chicória sobre a rúcula somente quando essa foi semeada a partir dos 15 DAT da chicória.

Assim, o sucesso da combinação da alface e rúcula está além das características genéticas dos grupos, associado também às peculiaridades do cultivo de 
Tabela 3. Matéria seca de rúcula $\left(\mathrm{g} \mathrm{m}^{-1}\right)$ em função da interação dos grupos de alface e sistema de cultivo e das épocas de semeadura da rúcula e sistema de cultivo no outono-inverno e na primavera . (Dry matter of roquette $\left(\mathrm{g} \mathrm{m}^{-1}\right)$ as result of the interaction of lettuce groups and cultivation system and sowing time of roquette and cultivation system in autumn-winter and spring). UNESP, Jaboticabal, SP, 2005.

\begin{tabular}{|c|c|c|c|c|c|}
\hline \multirow{3}{*}{ Sistemas de cultivo } & \multicolumn{5}{|c|}{ Outono-Inverno/matéria seca de rúcula $\left(\mathrm{g} \mathrm{m}^{-1}\right)$} \\
\hline & \multicolumn{5}{|c|}{ Grupos de alface } \\
\hline & \multicolumn{2}{|r|}{ Crespa } & Lisa & \multicolumn{2}{|r|}{ Americana } \\
\hline Consórcio & \multicolumn{2}{|r|}{$27,49 \mathrm{bA}^{1}$} & $23,08 \mathrm{bA}$ & \multicolumn{2}{|r|}{$25,18 \mathrm{aA}$} \\
\hline Cultivo solteiro & \multicolumn{2}{|r|}{33,89 aA } & 35,16 aA & \multicolumn{2}{|r|}{$28,58 \mathrm{aB}$} \\
\hline DMS & \multicolumn{2}{|r|}{ 4,22(linhas) } & \multicolumn{2}{|c|}{5,07 (colunas) } & \\
\hline \multirow{2}{*}{ Sistemas de cultivo } & \multicolumn{5}{|c|}{ Épocas de semeadura da rúcula (DAT) ${ }^{2}$} \\
\hline & \multicolumn{2}{|r|}{0} & 7 & \multicolumn{2}{|r|}{14} \\
\hline Consórcio & \multicolumn{2}{|r|}{$30,55 \mathrm{aA}$} & $26,06 \mathrm{bA}$ & \multicolumn{2}{|r|}{$19,14 \mathrm{bB}$} \\
\hline Cultivo solteiro & \multicolumn{2}{|r|}{30,96 aA } & 32,46 aA & \multicolumn{2}{|r|}{$34,22 \mathrm{aA}$} \\
\hline DMS & \multicolumn{2}{|r|}{5,07 (linhas) } & \multicolumn{2}{|c|}{4,22 (colunas) } & \\
\hline C.V. $(\%)$ & & & 17,79 & & \\
\hline \multirow{3}{*}{$\begin{array}{l}\text { Épocas de } \\
\text { semeadura da } \\
\text { rúcula }\end{array}$} & \multicolumn{5}{|c|}{ Primavera } \\
\hline & \multicolumn{2}{|c|}{ Sistemas de cultivo } & -Grunos de & \multicolumn{2}{|c|}{ Sistemas de cultivo } \\
\hline & Consórcio & Cultivo solteiro & Grupos de & Consórcio & Cultivo solteiro \\
\hline & \multicolumn{2}{|c|}{ Crespa } & & & $\mathrm{PT}^{2}$ \\
\hline 0 DAT & $26,90 \mathrm{bA}{ }^{1}$ & $27,34 a b A$ & Crespa & $26,90 \mathrm{aA}$ & $27,34 \mathrm{aA}$ \\
\hline 7 DAT & $40,75 \mathrm{aA}$ & $35,69 \mathrm{aA}$ & Lisa & $20,11 a A$ & $23,93 a A$ \\
\hline 14 DAT & $12,54 \mathrm{cB}$ & $21,79 \mathrm{bA}$ & Americana & $24,05 a A$ & $24,91 \mathrm{aA}$ \\
\hline & & isa & & & DAT \\
\hline$\overline{0 \text { DAT }}$ & $20,11 \mathrm{bA}$ & $23,93 \mathrm{bA}$ & Crespa & $40,75 a \mathrm{~A}$ & $35,69 \mathrm{cA}$ \\
\hline 7 DAT & $49,45 \mathrm{aA}$ & $47,94 \mathrm{aA}$ & Lisa & $49,45 a A$ & $47,94 \mathrm{bA}$ \\
\hline 14 DAT & $6,74 \mathrm{cB}$ & $24,72 \mathrm{bA}$ & Americana & $43,53 a \mathrm{a}$ & $61,34 \mathrm{aA}$ \\
\hline & & icana & & & DAT \\
\hline$\overline{0 \text { DAT }}$ & $24,05 \mathrm{bA}$ & $24,91 \mathrm{bA}$ & Crespa & $12,54 \mathrm{aB}$ & $21,79 b A$ \\
\hline 7 DAT & $43,53 \mathrm{aB}$ & $61,34 \mathrm{aA}$ & Lisa & $6,74 a \mathrm{~B}$ & $24,72 \mathrm{aA}$ \\
\hline 14 DAT & $9,58 \mathrm{cB}$ & $31,70 \mathrm{bA}$ & Americana & $9,58 \mathrm{aB}$ & $31,70 \mathrm{aA}$ \\
\hline$\overline{D M S}$ & & linhas) & & & olunas) \\
\hline C.V. (\%) & & & 18,84 & & \\
\hline
\end{tabular}

${ }^{1}$ Médias na mesma coluna, seguidas por letras minúsculas diferentes e na mesma linha, seguidas por letras maiúsculas distintas, diferem significativamente a 5\% de probabilidade pelo Teste de Tukey, ${ }^{2} \mathrm{DAT}=$ dias após o transplante da alface $\left({ }^{1}\right.$ For each interaction, means in the column followed by little different letters, and in the same line followed by head letters, differ significantly through Tukey test, 5\% probability; ${ }^{2} \mathrm{DAT}=$ days after transplanting date of lettuce).

cada grupo. Nesse caso, o maior espaçamento entrelinhas da alface americana foi decisivo para não afetar negativamente a rúcula quando essa foi semeada até 7 dias após o transplante da alface americana cv. Tainá. O arranjamento entre as culturas deve variar de acordo com o grupo e a época de estabelecimento do sistema. De acordo com Horwith (1985), quando a distância entre plantas atinge um ponto crítico, elas começam a competir por alguns ou todos os recursos do meio e a competição pela luz é citada por Portes (1984) como sendo a mais comum entre as plantas nos sistemas consorciados, superando a competição por água e nutrientes.

No outono-inverno, constatou-se que o consórcio estabelecido com a semeadura da rúcula a 0 DAT da alface lisa (cv. Elisa) foi o mais viável. Quando o consórcio teve início, aos 7 DAT, melhor resultado foi obtido com a alface do grupo americana (cv. Tainá). Aos 14 DAT, as diferenças morfológicas entre os grupos não promoveram efeito sobre as plantas de rúcula, de modo que independente do grupo de alface, a produção da matéria fresca da rúcula em consórcio foi inferior à obtida no cultivo solteiro (Tabela 2). Segundo Pitelli \& Durigan (1984), no início do ciclo da cultura da comunidade infestante, essas podem coabitar por um determinado período sem que haja uma interferência expressiva de uma sobre a outra.

Na primavera, houve interação significativa entre os fatores grupos de alfaces e sistemas de cultivo, e de grupos de alfaces com as épocas de semeadura da rúcula, e entre os sistemas de cultivo e as épocas de semeadura da rúcula
(Tabela 2). Os consórcios referentes aos grupos lisa e americana promoveram redução na matéria fresca da rúcula, diferente do que aconteceu quando a rúcula foi consorciada com alface crespa. Essa associação proporcionou maior matéria fresca de rúcula entre os consórcios estabelecidos com os três grupos, embora não tenha diferido do consórcio com a alface americana. Sendo assim, na primavera, o consórcio entre a alface crespa e rúcula apresentou-se mais adequado quando comparado aos outros consórcios, denotando não ter havido competição interespecífica ou ter sido insignificante. Diante dos resultados, nota-se que houve diferença entre as duas épocas de cultivo para a melhor associação das culturas, visto que no outono-inverno o melhor consórcio foi o de alface 'Elisa' 
Tabela 4. Produtividade $\left(\mathrm{kg} \mathrm{ha}^{-1}\right)$, e uso eficiente da terra (UET), em função das épocas de plantio, grupos de alfaces, sistemas de cultivo e das épocas de estabelecimentos do consórcio (Yield $\left(\mathrm{kg} \mathrm{ha}^{-1}\right)$ and efficient use of land $\left(\mathrm{kg} \mathrm{ha}^{-1}\right)$ as result of planting date, groups of lettuce, cultivation systems and time of implanting of consortium). UNESP, Jaboticabal, 2005.

\begin{tabular}{|c|c|c|c|c|c|c|}
\hline \multirow{2}{*}{ Tratamentos } & \multicolumn{2}{|c|}{ Produtividade } & \multirow{3}{*}{ UET $^{2}$} & \multicolumn{2}{|c|}{ Produtividade } & \multirow{3}{*}{ UET } \\
\hline & Alface & Rúcula & & Alface & Rúcula & \\
\hline Alface Crespa & \multicolumn{2}{|c|}{ Outono-inverno } & & \multicolumn{2}{|c|}{ Primavera } & \\
\hline Consórcio 0 DAT1 & 15.750 & 4.750 & 1,93 & 31.750 & 10.937 & 1,62 \\
\hline Consórcio 7 DAT & 15.250 & 2.687 & 1,20 & 34.500 & 9.937 & 1,84 \\
\hline Consórcio 14 DAT & 16.250 & 3.375 & 1,37 & 34.437 & 3.875 & 1,41 \\
\hline Solteiro da alface & 17.375 & - & 1,00 & 35.250 & - & 1,00 \\
\hline Solteiro da rúcula 0 DAT & - & 4.625 & 1,00 & - & 15.187 & 1,00 \\
\hline Solteiro da rúcula 7 DAT & - & 8.375 & 1,00 & - & 11.562 & 1,00 \\
\hline Solteiro da rúcula 14DAT & - & 7.750 & 1,00 & - & 8.937 & 1,00 \\
\hline \multicolumn{7}{|l|}{ Alface Lisa } \\
\hline Consórcio 0 DAT1 & 16.687 & 6.375 & 1,80 & 37.062 & 8.187 & 1,66 \\
\hline Consórcio 7 DAT & 15.750 & 3.312 & 1,45 & 31.562 & 12.062 & 1,65 \\
\hline Consórcio 14 DAT & 15.375 & 2.312 & 1,29 & 33.875 & 20.620 & 1,15 \\
\hline Solteiro da alface & 15.500 & - & 1,00 & 35.937 & - & 1,00 \\
\hline Solteiro da rúcula 0 DAT & - & 8.875 & 1,00 & - & 13.000 & 1,00 \\
\hline Solteiro da rúcula 7 DAT & - & 7.687 & 1,00 & - & 15.562 & 1,00 \\
\hline Solteiro da rúcula 14DAT & - & 7.875 & 1,00 & - & 10.187 & 1,00 \\
\hline \multicolumn{7}{|l|}{ Alface Americana } \\
\hline Consórcio 0 DAT1 & 33.375 & 2.312 & 1,27 & 43.000 & 6.562 & 1,34 \\
\hline Consórcio 7 DAT & 37.562 & 3.062 & 1,54 & 35.687 & 7.062 & 1,10 \\
\hline Consórcio 14 DAT & 34.437 & 1.375 & 1,12 & 43.187 & 19.370 & 1,05 \\
\hline Solteiro da alface & 36.062 & - & 1,00 & 48.000 & - & 1,00 \\
\hline Solteiro da rúcula 0 DAT & - & 6.750 & 1,00 & - & 14.750 & 1,00 \\
\hline Solteiro da rúcula 7 DAT & - & 6.125 & 1,00 & - & 19.937 & 1,00 \\
\hline Solteiro da rúcula 14DAT & - & 8.437 & 1,00 & - & 13.000 & 1,00 \\
\hline
\end{tabular}

${ }^{1}$ Dias após o transplante da alface; ${ }^{2} \mathrm{UET}=(\mathrm{Yab} / \mathrm{Yaa})+(\mathrm{Yba} / \mathrm{Ybb}), \mathrm{Yab}=$ produção da cultura "a" em consórcio com "b"; Yaa= produção da cultura "a" em cultivo solteiro; Yba= produção da cultura "b" em consórcio com "a" e Ybb= produção da cultura "b" em cultivo solteiro ('Days after lettuce transplanting; ${ }^{2} \mathrm{UET}=(\mathrm{Yab} / \mathrm{Yaa})+(\mathrm{Yba} / \mathrm{Ybb}), \mathrm{Yab}=$ yield of the culture "a" in the consortium with "b"; Yaa= yield of the single culture "a"; Yba= yield of the culture "b" consorted with "a"; Ybb= yield of the single culture "b").

do grupo lisa a 0 DAT, e na primavera foi rúcula com alface crespa cv. Vera.

Segundo a interação entre os grupos de alface e as épocas de semeadura da rúcula, foi observado que quando a semeadura da rúcula foi realizada aos 0 e 7 DAT da alface, a sua matéria fresca foi superior à semeadura aos 14 DAT. Quanto aos diferentes grupos de alface, verificou-se que apenas aos 7 DAT a matéria fresca da rúcula em relação à alface crespa foi diferente estatisticamente, promovendo redução na matéria fresca da rúcula de aproximadamente $22 \%$ em relação à alface lisa e de $27 \%$ da americana (Tabela 2).

Pela interação entre os sistemas de cultivo e as épocas de semeadura da rúcula (Tabela 2), a matéria fresca de rúcula não diferiu entre os sistemas de cultivo ao 0 e 7 DAT da alface, mas aos 14 DAT no sistema de consórcio houve redução de $63 \%$ na sua matéria fresca. Esta época proporcionou as menores produções, independente do sistema de cultivo, e certamente houve efeito desfavorável do ambiente sobre a rúcula. No período da primavera, ocorre elevação das temperaturas com o decorrer dos dias na estação. Após a semeadura da rúcula aos 14 DAT da alface, a temperatura ultrapassou $30^{\circ} \mathrm{C}$. Ainda na primeira metade do ciclo da rúcula, semeada, aos 14 DAT houve dias seguidos com temperaturas máximas de 34,0 a $35,6^{\circ} \mathrm{C}$, o que, possivelmente, promoveu efeito negativo no desenvolvimento da rúcula.

Comparando-se as matérias obtidas pelos consórcios estabelecidos aos 0,7 e 14 DAT; assim como no cultivo do outono-inverno, na primavera, o consórcio aos 14 DAT da alface, independente do grupo, proporcionou redução na matéria fresca da rúcula em relação aos consórcios estabelecidos mais cedo. A ausência de diferença entre as produções de matéria fresca de rúcula em consórcios estabelecidos aos 0 e 7 DAT da alface e seus respectivos culti- vos solteiros vem mais uma vez comprovar que ambas culturas não competem entre si pelos recursos do meio de cultivo, constituindo-se em plantas companheiras para as condições avaliadas.

Também houve interação significativa entre os tratamentos e as épocas de cultivo também para a matéria seca. A matéria seca da rúcula, no outono-inverno, foi influenciada pela interação entre os fatores grupos de alfaces e sistemas de cultivo, e entre os sistemas de cultivo e as épocas de semeadura da rúcula (Tabela 3 ). Em cultivo consorciado, a matéria seca de rúcula não diferiu da obtida em presença da alface, dos grupos crespa, lisa ou americana. Por outro lado, menores matérias secas de rúcula foram observadas em consórcio que no cultivo solteiro com alface crespa e lisa. $\mathrm{O}$ fato do consórcio estabelecido com a alface americana não ter diferido do cultivo solteiro, foi devido possivelmente ao maior espaçamento existente nesse tratamento. 
Nestas condições, as plantas de alface e de rúcula foram capazes de produzir fotossintatos suficientes para o seu crescimento, com conseqüente acúmulo de matéria seca igual ao do cultivo solteiro.

Avaliando-se os efeitos dos sistemas de cultivo e da época de semeadura da rúcula ainda no outono-inverno, a produção de matéria seca da rúcula quando semeada a 0 DAT não diferiu entre os sistemas de cultivo. No entanto, aos $7 \mathrm{e}$ 14 DAT, o cultivo solteiro foi mais eficiente do que o consórcio. No consórcio estabelecido em 14 DAT, houve redução de 37,34\% na produção da matéria seca da rúcula. Estes resultados, provavelmente, estão relacionados com a matéria fresca de rúcula nessa época de plantio (outono-inverno). Com exceção do consórcio com a alface americana, a 0 DAT, os demais não sofreram efeito competitivo pela alface, vindo a ocorrer redução da matéria fresca a partir dos 7 DAT. Independente do grupo, houve queda na matéria seca quando o consórcio foi estabelecido aos 14 DAT devido à competição da rúcula com a alface, quando o consórcio foi estabelecimento mais tardiamente.

Durante a primavera, verificou-se interação entre os fatores grupos de alfaces, sistemas de cultivo e época de semeadura da rúcula sobre a massa seca de rúcula (Tabela 3). Em sistema consorciado, maiores matérias secas de rúcula foram obtidas independente do grupo de alface, quando a rúcula foi semeada aos 7 DAT da alface. No entanto, comportamento da matéria seca de rúcula foi semelhante para cultivos solteiros, denotando ter havido, assim como para a matéria fresca, interferência dos picos de temperatura (acima de $30^{\circ} \mathrm{C}$ ) que comprometeram o desempenho das plantas de rúcula semeada aos 0 e 14 DAT, ou que a ausência de picos acima de $30^{\circ} \mathrm{C}$ (principalmente até a metade do ciclo) tenha favorecido as plantas da semeadura realizada aos 7 DAT. Contudo, os piores resultados para matéria seca de rúcula foram mesmo obtidos quando a semeadura dessa hortaliça ocorreu aos 14 DAT da alface. Mesmo havendo possível efeito da temperatura que tenha contribuído para a redução da matéria seca da rúcula, notase que a redução nesta época foi mais intensa em rúcula consorciada do que em cultivo solteiro. Para todos os grupos de alface, a produção de matéria seca de rúcula foi sempre inferior à obtida em consórcio aos 14 DAT.

Com base nos índices de uso eficiente da terra (UET), todos os consórcios foram viáveis (Tabela 4). No outonoinverno, o consórcio estabelecido a 0 DAT com as alfaces dos grupos crespa e lisa e aos 7 com alface americana, apresentaram os maiores UET. Na primavera os maiores valores ocorreram aos 7 DAT para crespa e lisa e a 0 DAT para o grupo americana. Os valores máximos de UET atingidos foram entre a alface crespa e a rúcula nas duas épocas, sendo ao zero e aos 7 DAT no outono-inverno $(1,93)$ e na primavera $(1,84)$, respectivamente, correspondendo à produção de $93 \%$ ou $84 \%$ a mais de rúcula e alface em 1 ha de consórcio em relação à mesma área de cultivos solteiros, ou seja, somando-se as produções de 0,5 ha de alface e 0,5 ha de rúcula.

\section{REFERÊNCIAS}

ADELANA BO. 1984. Evaluation of maizetomato mixed-cropping in South-Western Nigeria. Indian Journal of Agricultural Science 54: 564-569.

BEZERRA NETO F; ANDRADE FV; NEGREIROS MZ; SANTOS JÚNIOR JJ. 2003. Desempenho agroeconômico do consórcio cenoura $\mathrm{x}$ alface lisa em dois sistemas de cultivo em faixa. Horticultura Brasileira 21: 635-641.

BRANCO RBF. 2001. Avaliação de cultivares e épocas de cultivo de alface, nas condições de solo e hidroponia, em ambiente protegido. Jaboticabal: Unesp-FCAV. 80 f (Dissertação de Mestrado)

BRUNINI O; LISBÃO RS; BERNARDI JB; FORNASIER JB; PEDRO JÚNIOR MJ. 1976. Temperatura-base da alface (Lactuca sativa L.) cultivar 'White Boston' em um sistema de unidades térmicas. Revista de Olericultura 35: 213-219.

CAETANO LC; FERREIRA JM; ARAÚJO ML. 1999. Produtividade de cenoura e alface em sistema de consorciação. Horticultura Brasileira 17: 143-146.

CARVALHO AJC. 1993. Comportamento de cultivares e linhagens de soja (Glycine max $(L$.) Merrill.) em consórcio com milho (Zea mays L.) de ciclos e portes diferentes. $70 \mathrm{f}$. Lavras: ESAL. 70 f. (Dissertação de Mestrado).

CECÍlIO FILHO AB; MAY A. 2002. Produtividade das culturas de alface e rabanete em função da época de estabelecimento do consórcio. Horticultura Brasileira 20: 501-504.

CECÍLIO FILHO AB; TAVEIRA MCGS; GRANGEIRO LC. 2003. Productivity of the beet culture in function of time of establishment of the intercropping with roquette. Acta Horticulturae 607: 91-95.

FIGUEIREDO, EB; MALHEIROS EB; BRAZ LT. 2004. Interação genótipos x ambiente em cultivares de alface na região de Jaboticabal. Horticultura Brasileira 22: 66-71.
FRANÇA TF; LEEUWEN R; CECÍLIO FILHO AB. 2004. Viabilidade produtiva do cultivo consorciado de chicória e rúcula em função da época de estabelecimento do consórcio. Horticultura Brasileira, 22:2, Suplemento 2. CD-ROM.

GLIESSMAN S. 2004. Mixing broccoli and lettuce in an intercrop creates complementary patterns of resource use. In: BLEY, C. Broccoli/Lettuce Intercropping in California, USA, 1999. Disponível em: <http:// agroecology.org/cases/broclettuce.htm>. Acessado em 01 de junho de 2004.

HORWITH B. 1985 A role for intercropping in modern agriculture.. BioScience 35: 286-291.

NARDIN RR; CATELAN F; CECILIO FILHO AB. 2002. Efeito da consorciação sobre as produtividades da rúcula e da beterraba estabelecida por transplantio de mudas. Horticultura Brasileira 20; Suplemento. cd-ROM.

PITELLI RA; DURIGAN JC. 1984. Terminologia para períodos de controle e de convivência das plantas daninhas em culturas anuais e bianuais. In: CONGRESSO BRASILEIRO DE HERBICIDAS E PLANTAS DANINHAS, 15. Anais... Belo Horizonte: SBCPD. 37p.

PORTES TA. 1984. Aspectos ecofisiológicos do consórcio milho $\mathrm{x}$ feijão. Informe agropecuário, 10: 30-34.

REZENDE BL. 2004. Análise produtiva e rentabilidade das culturas de pimentão, repolho, rúcula, alface e rabanete em cultivo consorciado. Jaboticabal: UNESP-FCAV. 60 f. (Dissertação de Mestrado).

REZENDE BA; CECÍLIO FILHO AB; CANATO GHD; MARTINS MIEG. 2005a. Análise econômica de consórcios de alface $\mathrm{x}$ tomate, em cultivo protegido, em Jaboticabal (SP). Científica 33: 9-14.

REZENDE BLA; CECÍLIO FILHO AB; MARTINS MIEG; COSTA CC; FELTRIM AL. 2005b. Viabilidade econômica das culturas de pimentão, repolho, alface, rabanete e rúcula em cultivo consorciado. Informações Econômicas 35: 22-37.

REZENDE BLA; COSTA CC; CECÍLIO FILHO AB; MARTINS MIEG; SILVA GS. 2005c. Custo de produção e rentabilidade da alface crespa, em ambiente protegido, em cultivo solteiro e consorciado com tomateiro, Jaboticabal, Estado de São Paulo. Informações Econômica 35: 42-50.

SOETEDJO P; MARTIN LD; TENNANT D. Productivity and water use of intercrops of field pea and canola. In: AUSTRALIAN AGRONOMY CONFERENCE, v. 9., 1998, California. Disponível em: <http:// www.regionaI.org.au/au/asa/1998/5/ 138 soetedjo.htm $>$. Acessado em 06 maio de 2005.

TOLENTINO JUNIOR CF; ZÁRATE NAH; VIEIRA MC. 2002. Produção de mandioquinha-salsa consorciada com alface e beterraba. Acta Scientiarum 24: 1447-1454.

TRANI PE; PASSOS FA; AZEVEDO FILHO JA. 1997. Alface, almeirão, chicória, escarola, rúcula e agrião d'água. In: RAIJ B; CANTARELLA H; QUAGGIO JA; FURLANI AMC. Recomendação de adubação e calagem para o Estado de São Paulo. 2 ed. Campinas: IAC. p.168-169. (Boletim Técnico, 100)

ZAFFARONI E; DINIZ MS; SANTOS EB. 1987. Yield stability of sole and intercropping systems in the Northeast of Brazil. Pesquisa Agropecuária Brasileira 22: 393-399.

WILLEY RW. 1979. Intercropping: its importance and research needs. Part 1. Competition and yield advantages. Field Crops Abstract 32: 1-10. 